\title{
Formulation, Development and Evaluation of Fast Dissolving Oral Film of a Atenolol Drug and validation by RP-HPLC Method using ICH Q2 guidelines
}

\author{
Balu S. Khandare* and Komal S. Wagh \\ Kasturi Shikshan Sanstha College of Pharmacy Shikrapur Pune, Maharashtra, India-412208
}

\begin{abstract}
Now a days, fast dissolving dosage forms are gaining popularity, as this dosage form can be administered without water. Rapid dissolving property, avoiding first pass metabolism and majority of the drug is absorbed through buccal/oral mucosa in to systemic circulation. On oral administration of atenolol undergoes first pass metabolism results in reduced bioavailability up to (60\%), so the objective of the present study was to formulate and evaluate fast dissolving oral films of atenolol to overcome the limitation of bioavailability and increase patient's compliance. In recent studies oral films were prepared by solvent casting method using HPMC K15 as a film formers and PEG 400, glycerin as plasticizers and evaluated for mechanical properties, disintegration and in vitro dissolution. Good mechanical properties and in vitro drug release were shown by all formulations. The Comparing to other formulations, the optimized (F5) Formulation (HPMC K15, CCS and PEG 400) Exhibited drug release of $92.12 \%$ in 15 minutes which was significantly high. RP-HPLC is simple, fast, precise, sensitive, and reproducible (liquid chromatography) method was developed and validated for the analysis of atenolol drug formulation. Using C-18 HPLC column separation was carried out. This was maintained at ambient temperature. Analysis was carried out by using UV detector at the wavelength 228 $\mathrm{nm}$. The RP-HPLC method was found to be linear over the concentration ranges from $50-100 \mu \mathrm{g} / \mathrm{mL}\left(\mathrm{r}^{2}=0.999\right)$. Retention time for atenolol drug formulation was found to be $5.496 \mathrm{~min}$. LOQ of method was $5.7308 \mu \mathrm{g} / \mathrm{mL}$ and LOD $2.5036 \mu \mathrm{g} / \mathrm{mL}$.
\end{abstract}

Keywords: Atenolol, Fast dissolving oral film, Bioavailability, Mechanical properties, C18, RP-HPLC, Methanol

Article Info: Received 14 June 2019; $\quad$ Review Completed 12 Aug 2019; $\quad$ Accepted 18 Aug $2019 ; \quad$ Available online 15 Sep 2019



Cite this article as:

Khandare BS, Wagh KS, Formulation, Development and Evaluation of Fast Dissolving Oral Film of a Atenolol Drug and validation by RP-HPLC Method using ICH Q2 guidelines , Journal of Drug Delivery and Therapeutics. 2019; 9(5):99-104 http://dx.doi.org/10.22270/jddt.v9i5.3582

Balu S. Khandare, Kasturi Shikshan Sanstha College of Pharmacy Shikrapur Pune, Maharashtra, India-412208

\section{INTRODUCTION}

In the pharmaceutical industry rapidly dissolving or quick dissolving dosage forms have acquired great importance due to their unique properties and advantages. Within a minute these systems either dissolve or disintegrate, on contact little quantity of water or by chewing. This delivery system consists of a thin film, which is simply placed on the patient's tongue or mucosal tissue, instantly wet by saliva; the film rapidly dissolves. Then it rapidly disintegrates and dissolves to release the medication for oral mucosal absorption. The major portion of the active ingredient is swallowed orally along the saliva and absorption takes place in the gastrointestinal tract subsequently making them particularly suitable for pediatrics and geriatric patients. In 1970'sthe fast dissolving films were introduced as an alternative to the conventional tablet and capsule which require swallowing of the dosage form ${ }^{1}$.By researchers the rapidly dissolving dosage forms are referred by various names such as quick disintegrating, orally disintegrating, mouth dissolve or melt in mouth dosage forms. There are specific advantages of these dosage forms including no need of water for disintegration, accurate dosing, ease of transport, handling, acceptable taste, rapid onset of action and patient compliance $^{2}$. The trans mucosal deliveries of metformin, dexa-methasone and levo-cetrizine hydrochloride have proved their enhanced bioavailability over the conventional formulations. ${ }^{8}$ Solvent casting was proved to be reliable technique for the manufacturing of fast dissolving films. By this method the film strips prepared undergo instantaneous disintegration upon placing in buccal/oral cavity. The plasticizers present in fast dissolving films formulation, reduce the glass transition temperature and thereby enabling desired film qualities ${ }^{3-6}$. Atenolol is chemically $(R S)$ 2-\{4-[2-Hydroxy-3-(propan-2-ylamino) propoxy] phenyl $\}$ acetamide. Atenolol is a beta blocker medication primarily used to treat high blood pressure and heart-associated chest pain. Other uses include the prevention of migraines and treatment of certain irregular heart beats. It is taken by mouth or by injection into a vein. It can also be used with other blood pressure medications. Common side effects include feeling tired, heart failure, dizziness, depression, 
and shortness of breath. Other serious side effects include bronchospasm. It is not recommended during pregnancy. Other medications are preferred when breastfeeding a young baby. It works by blocking $\beta 1$ adrenergic receptors in the heart, thus decreasing the heart rate and workload. Atenolol is used for a number of conditions including hypertension, angina, long QT syndrome, acute myocardial infarction, supraventricular tachycardia, ventricular tachycardia, and the symptoms of alcohol withdrawal. Initial investigations were focused on the development of placebo fast dissolving films with good peel ability, appearance and a quick disintegration time. After choosing the components for the placebo film, atenolol loaded films were formulated. Although, fast dissolving film is an attractive dosage form for the delivery of atenolol. Finally, HPMC and CCS were formulated and evaluated using fast dissolving films ${ }^{9}$.

\section{MATERIAL AND METHOD}

Atenolol was received as a gift sample from Mylan Laboratories Limited, Hyderabad, India. HPLC grade methanol, ethanol and double distilled water as solvent were used for the other purpose. HPMC K15M, PEG-400, SSG, CCS was obtained from Mapromax, Life sciences Pvt. Ltd. Dehradun. Aspartame, citric acid was obtained from Loba Chemical Pvt Ltd (Mumbai, India). Hydrochloric acid was obtained from S. D. Fine Chem. Ltd., Mumbai. All other chemical were purchased from Hi Media, Mumbai. All other chemicals used in this study including those stated were of analytical reagent (A.R.) grade.

\section{Drug-excipient compatibility study}

FTIR spectra of pure drugs, polymers used, and blends were recorded on $\mathrm{KBr}$ disk method using Brukers Alpha Spectrophotometer with IR solution software to confirm the compatibility between drug and excipient. Sample powder was thoroughly mixed by triturating with potassium bromide in a glass mortar with pestle and compressed into disks in a hydraulic press (Techno search Instruments, India). Over a spectral region from 4700 to $400 \mathrm{~cm}-1$ using 20 scans with $4 \mathrm{~cm}-1$ resolution, FTIR spectra of all the samples were recorded.

\section{Preparation of oral films}

Drug (atenolol) containing fast dissolving films were fabricated by the solvent casting method. The optimized amount of HPMC was dissolved in $5 \mathrm{~mL}$ of water and stirrer continuously for 1 hour, optimized amount of Plasticizer and drug were dissolved in $95 \%$ ethanol and then added to the polymeric solution, Polymeric solution was stirred for 30 min using magnetic stirrer and was kept in undisturbed condition till the entrapped air bubbles were removed. The aqueous solution was casted in a glass moulds having $2.5 \mathrm{x}$ $2.5 \mathrm{~cm}, 10$ films area and was dried at controlled room temperature $\left(25-30^{\circ} \mathrm{C}, 45 \% \mathrm{RH}\right)$ as well as at increased temperature (microwave oven). The film took approximately $48 \mathrm{hr}$ to dry at controlled room temperature. The dried film was carefully removed from the glass plates and was cut into size required for testing. The films were stored in air tight plastic bags till further use. Formulations were prepared using HPMC K15, PEG-400, SSG and CCS at different drug: polymer ratios $2,5-6$. The compositions of the formulations were shown in table 1.

Table 1. Formulation of Atenolol oral fast dissolving films

\begin{tabular}{|c|c|c|c|c|c|c|}
\hline $\begin{array}{c}\text { Name of ingredients } \\
\text { (mg for 12 strips) }\end{array}$ & F1 & F2 & F3 & F4 & F5 & F6 \\
\hline Atenolol (mg) & 500 & 500 & 500 & 500 & 500 & 500 \\
\hline HPMC K15 (mg) & 700 & 80 & 1100 & 700 & 80 & 1100 \\
\hline Glycerin (mg) & - & - & - & - & - & - \\
\hline PEG-400 (mg) & 80 & 80 & 80 & 80 & 80 & 80 \\
\hline SSG (mg) & 150 & 200 & 300 & - & - & - \\
\hline CCS (mg) & - & - & - & 200 & 300 & 400 \\
\hline Aspartame (mg) & 50 & 50 & 50 & 50 & 50 & 50 \\
\hline Citric acid (mg) & 110 & 110 & 110 & 110 & 110 & 110 \\
\hline DM water qs to (m) & - & - & - & - & - & - \\
\hline
\end{tabular}

\section{Evaluation}

The formulations were evaluated by the following tests.

\section{Thickness}

Randomly 20 films were selected and thickness was measured using vernier caliber at three different places.

\section{Weight variation}

For each formulation, three randomly selected patches were used. For weight variation test, 20 films from each batch were weighed individually by digital electronic balance and the average weight was calculated.

\section{Drug content analysis}

The patches $(n=3)$ of specified area were taken into a $10 \mathrm{ml}$ volumetric flask and dissolved in methanol and volume was made up with $10 \mathrm{ml}$ methanol. Subsequent dilutions were made and analyzed by UV spectrophotometer.

\section{Folding endurance}

This was determined by repeatedly folding one film at the same place until it broke. The number of times the film could be folded at the same place without breaking cracking gave the value of folding endurance.

\section{Percentage of moisture content}

The films were weighed individually and kept in desiccators containing activated silica at room temperature for $24 \mathrm{hrs}$. Individual films were weighed repeatedly until they showed a constant weight. The percentage of moisture content was calculated as the difference between initial and final weight.

\section{In vitro dissolution study}

The in vitro dissolution test was performed using the USPXXX dissolution apparatus II (Paddle with sinker). The dissolution studies were carried out at $37 \pm 0.5^{\circ} \mathrm{C}$; with stirring speed of $50 \mathrm{rpm}$ in $900 \mathrm{ml}$ phosphate buffer $(\mathrm{pH}$ $6.8)$. Film size required for dose delivery $(2.5 \times 2.5 \mathrm{~cm} 2)$ was used. Five $\mathrm{ml}$ aliquot of dissolution media was collected at 
time intervals of $1,2,5,10$ and 15 minutes and replaced with equal volumes of phosphate buffer ( $\mathrm{pH}$ 6.8). The collected samples were filtered through $0.45 \mu \mathrm{m}$ membrane filter and the concentration of the dissolved atenolol was determined using UV-Visible spectrophotometer at $228 \mathrm{~nm}$. The results were presented as an average of three such concentrations ${ }^{4}$.

\section{Stability studies}

Stability studies were carried out with optimized formulation which was stored for a period of one, two and three months at $40 \pm 20 \mathrm{C}$ temperature and $75 \pm 5 \%$ relative humidity for a period 3 months. The \% Assay of formulation was determined by U.V. spectrophotometer using calibration curve method. The \% assay of film was found to slightly decrease at higher temperature.

\section{Physical appearance and texture analysis of the films}

These parameters were checked simply with visual infection of films and by feel or touch.

\section{In vitro disintegration}

The film of $(4.15 \mathrm{~cm} 2)$ size (unit dose) was placed on a Petridis containing $10 \mathrm{ml}$ of distilled water. The time required for the film to break was noted as cursive in vitro disintegration time.

\section{Measurement of mechanical properties}

Microprocessor based advanced force gauge tensiometer (DS 2 series) equipped with a $50 \mathrm{~kg}$

load cell was used to determine the mechanical properties of OFDFs. Film of $60 \times 10 \mathrm{~mm} 2$ was fixed between two clamps separated by a distance of $3 \mathrm{~cm} 17$. The lower clamp was held stationary and the strips were pulled apart by the upper clamp moving at a rate of $2 \mathrm{~mm} / \mathrm{sec}$ until the strip broke. The force and elongation of the film at the point when the strip broke was recorded. The tensile strength and percent elongation values were calculated using the following formula.

Tensile strength $=$ load at breakage $/$ film thickness $\times$ film width

\section{$\%$ Elongation $=$ increase in length $\times 100 /$ original length}

\section{HPLC METHOD VALIDATION}

\section{Determination of working wavelength $(\lambda \max )$}

$10 \mathrm{mg}$ of atenolol was weighed and transferred in to $100 \mathrm{~mL}$ volumetric flask and dissolved in methanol and then make a dilution of that stock solution. Prepare $10 \mu \mathrm{g} / \mathrm{mL}$ solutions by diluting $1 \mathrm{~mL}$ to $10 \mathrm{~mL}$ with methanol. Wavelength of maximum absorption for $10 \mu \mathrm{g} / \mathrm{mL}$ solution of the bulk drug in methanol was scanned using UV-Visible spectrophotometer within the range of 200-400 nm wavelength with methanol as reference. The absorption curve shows at $228 \mathrm{~nm}$ for atenolol formulation ${ }^{11-16}$.

\section{Linearity}

For the linearity study were prepared suitable dilution (ranging from 50-100 $\mu \mathrm{g} / \mathrm{mL}$ ) of standard stock solution using mobile phase. Though linear response was obtained at lower concentrations for atenolol and higher concentration range was used to improve signal to noise ratio. Linearity was determined by analyzing five working standard solutions over the concentration range of $50-100 \mu \mathrm{g} / \mathrm{mL}$ for drug formulation concentration ${ }^{17-20}$.

\section{Limit of detection (LOD)}

The limit of detection (LOD) is the smallest concentration that can be detected but not necessarily quantified as an exact value. LOD is calculated from the formula,

$\mathrm{LOD}=3.3 \sigma / \mathrm{s}$

Where, $\sigma=$ standard deviation of the response

$\mathrm{S}=$ slope of the calibration curve.

\section{Limit of Quantification (LOQ)}

The limit quantification (LOQ) is the lowest amount of analyte in the sample that can be quantitatively determined with precision and accuracy. LOQ is calculated from formula,

$\mathrm{LOQ}=10 \sigma / \mathrm{s}$

Where, $\sigma=$ standard deviation of the response

$\mathrm{S}=$ slope of calibration curve

\section{Accuracy}

Accuracy of this method was carried out using one set of different standard addition methods at different concentration levels $80 \%, 100 \%$ and $120 \%$, and then comparing the difference between the spiked value (theoretical value) and actual found value.

\section{Precision}

Five sets of aliquots with same concentration $(90 \mu \mathrm{g} / \mathrm{mL})$ were prepared and these solutions were analyzed to record any intra and inter day variations in the results. The results obtained for Intra and inter day variations.

\section{Robustness}

Robustness of the proposed method for atenolol was carried out by the slight variation in flow rate, temperature and mobile phase ratio. The percentage recovery and RSD were noted for atenolol.

\section{Checking resolution of formulation}

The column was saturated with the mobile phase (indicated by constant back pressure at desired flow rate). Standard solution of atenolol was injected to get the chromatogram. The retention time for atenolol was found to be $5.496 \mathrm{~min}$. It is shown in the Table 2.

Table 2. Resolution of formulation

\begin{tabular}{|c|c|c|c|c|c|}
\hline Formulation & Ret. Time & Area & Height & Theoretical plate & Tailing factor \\
\hline Atenolol & 5.496 & 37957814 & 350811 & 3806.216 & 1.02 \\
\hline
\end{tabular}


Linearity:

The data of the peak area vs drug formulation concentration were evaluated by linear regression analysis as shown in the Table 3 and calibration curve obtained after plotting drug formulation concentration vs area shown in the fig.1 Linear regression analysis demonstrated that chromatograph response for the drug was highly linear $\left(r^{2}=0.999\right)$ in the studied concentration range of $50-100 \mu \mathrm{g} / \mathrm{mL}$. A typical chromatogram of atenolol ( $50 \mu \mathrm{g} / \mathrm{mL})$ shown in fig. 1 .

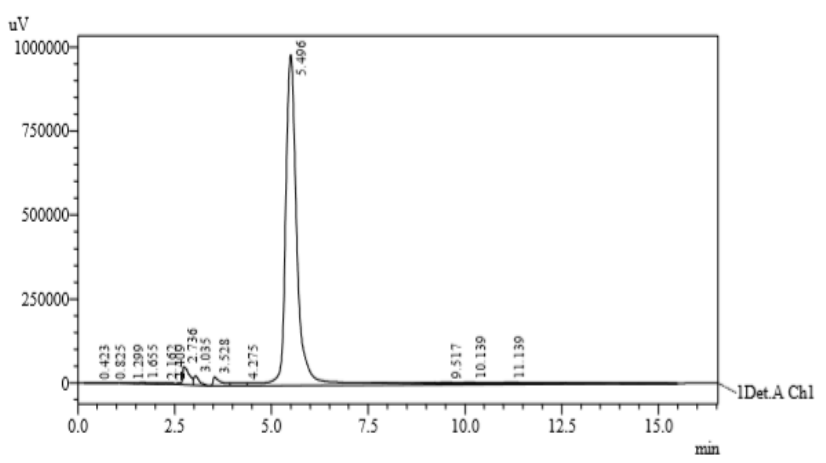

Fig.1 A typical chromatogram for drug formulation concentration $(50 \mu \mathrm{g} / \mathrm{mL})$

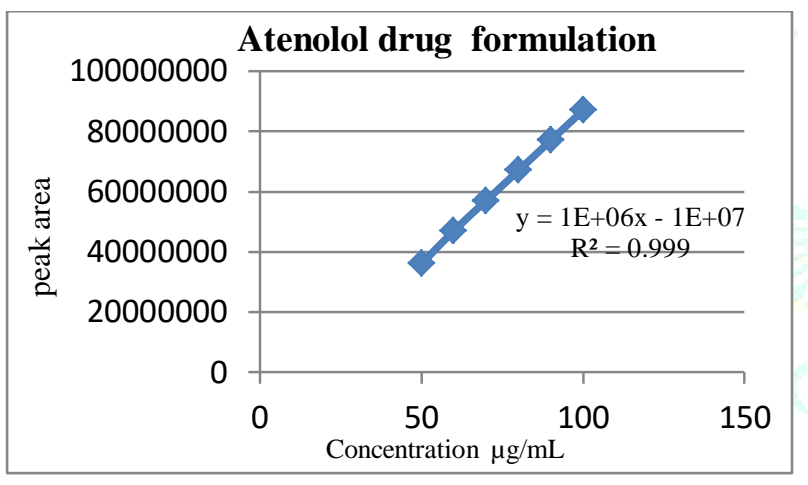

Fig.2 Calibration curve of atenolol formulation

Table 3. Calibration of atenolol formulation

\begin{tabular}{|c|c|c|}
\hline Sr no. & Concentration $(\boldsymbol{\mu g} \mathbf{g} \mathbf{m L})$ & Peak area \\
\hline 1 & 50 & 37957814 \\
\hline 2 & 60 & 47957814 \\
\hline 3 & 70 & 57987814 \\
\hline 4 & 80 & 68907814 \\
\hline 5 & 90 & 78957814 \\
\hline 6 & 100 & 88957814 \\
\hline
\end{tabular}

\section{Precision}

The result depicted in the table $6 a, 6 b$ indicated that the given method has sufficient precision as indicated by the corresponding values of \%RSD ranging 0.13 for inter day studies respectively. The values of \%RSD for both the studies are well below $1.0 \%$ constructing adequate precision.

\section{Limit of detection and quantification}

Standard error and slope of linear data is used to predict LOD and LOQ of atenolol and precision was established at the predict concentration. The result was shown in the table 7 .

\section{RESULT AND DISCUSSION}

Solubility of atenolol was freely soluble in various solvents like methanol and ethanol, also slightly soluble in $0.1 \mathrm{~N} \mathrm{NaOH}$, soluble in water, $0.1 \mathrm{~N} \mathrm{HCL}$ and $6.8 \mathrm{pH}$ phosphate buffers. The melting point of atenolol was $220-226^{\circ} \mathrm{C}$ and $\lambda$ max of atenolol was found to be $228.0 \mathrm{~nm}$ by using U.V. spectrophotometer (shimadzu-1800) the general appearance, assay, weight variation and thickness of all the films were within acceptable limits table 4 . The results for tensile strength, folding endurance, disintegrating time, \% elongation and $\%$ of moisture were shown in table 5 . Tensile strength value of optimized formulation (F5) was $1.324 \pm 0.065 \mathrm{~kg} / \mathrm{cm} 2$ and percent elongation $6.57 \pm 0.62$. The folding endurance of the optimized oral fast dissolving formulation (F5) was $132.35 \pm 6.45$. The formulations containing CCS were showing good results compared to SSG. The assay values of all the formulations were ranging from 90.25 to $98.89 \%$. The disintegration time was ranging between 52 to more than $92 \mathrm{sec}$. The final formulation shows better drug release $(92.12 \%)$ compared to other formulation within $15 \mathrm{~min}$ (Figure 3).From the stability studies it was clearly observed that the drug showed good stability after subjecting to accelerated stress conditions and the polymers shown significantly compatibility with the drug. The cumulative percentage $(\%)$ drug release profile and the assay of the F5 formulation films indicates that the drug remain stable under the ASC without any significant change in its release profile and the drug content..RP-HPLC methods were developed and validated as per ICH guidelines Q2 (R1). The proposed methods can be successfully applied for atenolol Fast Dissolving Oral Film without any interference in quality control.



Fig.3 In- vitro drug release study of Atenolol formulation

Table 4. Result of thickness and weight variation

\begin{tabular}{|c|c|c|c|c|}
\hline F. code & General Appearance & Thickness in $\boldsymbol{\mu m}$ & $\begin{array}{c}\text { Weight(mg) Mean } \\
\mathbf{\pm} \text { S.D }\end{array}$ & \% Assay \\
\hline F1 & Translucent & $88 \pm 2$ & $155 \pm 4$ & $90.25 \pm 0.14$ \\
\hline F2 & Translucent & $90 \pm 5$ & $158 \pm 3$ & $96.45 \pm 0.28$ \\
\hline F3 & Translucent & $92 \pm 5$ & $150 \pm 1$ & $95.65 \pm 0.36$ \\
\hline F4 & Translucent & $94 \pm 6$ & $152 \pm 2$ & $97.65 \pm 0.24$ \\
\hline F5 & Translucent & $95 \pm 4$ & $159 \pm 5$ & $98.89 \pm 0.14$ \\
\hline
\end{tabular}


Table 5 Result of folding endurance, disintegrating time, tensile strength, \% elongation \&\% of moisture content

\begin{tabular}{|c|c|c|c|c|c|}
\hline Code & $\begin{array}{c}\text { Folding } \\
\text { endurance } \\
\text { (Times) }\end{array}$ & $\begin{array}{c}\text { Disintegrating } \\
\text { time (Sec) }\end{array}$ & $\begin{array}{c}\text { Tensile strength } \\
\text { in kg/cm2 }\end{array}$ & $\begin{array}{c}\text { \% } \\
\text { elongation } \\
\text { Mean } \pm \text { S.D }\end{array}$ & $\begin{array}{c}\text { \% of moisture } \\
\text { content }\end{array}$ \\
\hline F1 & $103.33 \pm 9.87$ & $92 \pm 4$ & $0.620 \pm 0.056$ & $5.94 \pm 0.88$ & $0.698 \pm 0.111$ \\
\hline F2 & $105.25 \pm 4.56$ & $80 \pm 6$ & $0.680 \pm 0.045$ & $4.29 \pm 0.67$ & $0.647 \pm 0.101$ \\
\hline F3 & $99.33 \pm 7.67$ & $75 \pm 7$ & $1.212 \pm 0.012$ & $2.24 \pm 0.57$ & $0.897 \pm 0.142$ \\
\hline F4 & $111.02 \pm 8.55$ & $60 \pm 6$ & $1.542 \pm 0.045$ & $4.35 \pm 0.66$ & $0.998 \pm 0.156$ \\
\hline F5 & $132.35 \pm 6.45$ & $52 \pm 4$ & $1.324 \pm 0.065$ & $6.57 \pm 0.62$ & $0.898 \pm 0.136$ \\
\hline F6 & $120.66 \pm 5.29$ & $55 \pm 5$ & $1.269 \pm 0.045$ & $3.21 \pm 0.21$ & $0.956 \pm 0.145$ \\
\hline
\end{tabular}

Table 6a. Intra-day Precision for atenolol formulation

\begin{tabular}{|c|c|c|c|c|}
\hline Concentration $(\boldsymbol{\mu g} / \mathbf{m L})$ & Peak area & Mean (n=5) & S.D. & \%RSD \\
\hline 90 & 78957814 & & & \\
\hline 90 & 75620844 & & & \\
\hline 90 & 78528703 & 77468861 & 12822.96 & 0.14 \\
\hline 90 & 76429855 & & & \\
\hline 90 & 75069865 & & & \\
\hline
\end{tabular}

Table 6b. Inter-day Precision for atenolol formulation

\begin{tabular}{|c|c|c|c|c|}
\hline Concentration $(\boldsymbol{\mu g} / \mathbf{m L})$ & Peak area & Mean (n=5) & S.D. & \%RSD \\
\hline 90 & 78957745 & & & \\
\hline 90 & 75620896 & & & 0.15 \\
\hline 90 & 78528756 & 75100789 & 38917.53 & \\
\hline 90 & 76429789 & & & \\
\hline 90 & 75069896 & & & \\
\hline
\end{tabular}

Table 7 Limit of detection and Limit of quantification

\begin{tabular}{|c|c|}
\hline Limit of detection & Limit of quantification \\
\hline $2.5036 \mu \mathrm{g} / \mathrm{mL}$ & $5.7308 \mu \mathrm{g} / \mathrm{mL}$ \\
\hline
\end{tabular}

\section{CONCLUSION}

Oral fast dissolving films are more superior method to release drug. By using HPMC and PEG 400, the films are prepared and have shown good mechanical strength, to release drug, disintegrate the drug fast and also enhancement of stability of drug. From result F5 formulation is considered as the best according to got result with low disintegration time and complete the drug release with in 15 min. the percent drug release and disintegration time was taken as responses for study which were found within the accepted ranges. In these formulation as the concentration of CCS was increased, both the disintegration and the drug release rates also increased. The disintegration and release rates were found to be faster for films prepared with lowest concentration of HPMC also with maximum concentration of super disintegrates. For pediatric, geriatric and also for general population, atenolol being administered in the form of fast dissolving films will be potential novel drug dosage form by providing faster release and better patient compliance. In this paper described for the determination of atenolol in formulation is simple, sensitive and reproducible.

\section{ACKNOWLEDGEMENTS:}

The authors are grateful to, the Principal and the Management of Kasturi Shikshan Sanstha College of Pharmacy Shikrapur Pune. The authors are thankful to Mylan laboratories pvt. Ltd., Hyderabad (India) for providing gift sample.

\section{REFERENCES}

1. Liang, A.C. and Chen, L.L.H., 2001. Fast-dissolving intraoral drug delivery systems. Expert Opinion on Therapeutic Patents, 11(6), pp.981-986.

2. Borsadia, S.B., O'Halloran, D. and Osborne, J.L., 2003. Quick dissolving films-A novel approach to drug delivery. Drug Deliv Technol, 3(3), pp.63-6.

3. Galfetti, P. and Vollmer, U., 2006. Rapid film: Oral thin films as an innovative drug delivery System and dosage form. Drug Dev Report, pp.64-67.

4. Klancke, J., 2003. Dissolution testing of orally disintegrating tablets. Dissolution technologies, 10(2), pp.6-9.

5. Parakh, S.R. and Gothoskar, A.V., 2003. A review of mouth dissolving tablet technologies. Pharmaceutical technology, 27(11), pp.92-100.

6. Kunte, S. and Tandale, P., 2010. Fast dissolving strips: A novel approach for the delivery of verapamil. Journal of pharmacy and bioallied sciences, 2(4), p.325.

7. Sushma, M., Prasanna Raju, Y., Sundaresan, C.R., Vandana, K.R., Vijay Kumar, N. and Harini Chowdary, V., 2014. Transmucosal delivery of metformin-a comprehensive study. Current drug delivery, 11(2), pp.172-178.

8. Prabhu, P., Malli, R., Koland, M., Vijaynarayana, K., D’Souza, U., Harish, N.M., Shastry, C.S. and Charyulu, R.N., 2011. Formulation and evaluation of fast dissolving films of levocitirizine di hydrochloride. International journal of pharmaceutical investigation, 1(2), p.99.

9. Himabindu, S. and Sathish, D., 2012. Formulation and In-vitro Evaluation of Mucoadhesive Buccal Patches of Cyproheptadine Hydrochloride. Journal of Applied Pharmaceutical Science, 2(7), p.196.

10. Kolsure, A.K., Chavan, B.B., Chabukswar, A.R. and Kuchekar, B.S., 2014. Development and validation of a HPTLC method for 
simultaneous estimation of atorvastatin calcium and losartan Potassium in combined dosage form. Asian Journal of Biomedical and Pharmaceutical Sciences, 4(32), p.57.

11. Pant, S. and Pal, K., 2012. Development and Validation of a Simultaneous HPLC Method for Assay and Dissolution of Bisoprolol fumarate and Amlodipine besylate in Pharmaceutical Dosage. Research Journal of Pharmaceutical Dosage Forms and Technology, 4(1), p.62.

12. Choudhari, V.P., Suryawanshi, V.M., Mahabal, R.H., Deshchougule, S., Bhalerao, K. and Kuchekar, B., 2010. Simultaneous spectrophotometric estimation of Atenolol and Lercanidipine Hydrochloride in combined dosage form by ratio derivative and dual wavelength method. Int J Pharm Sci Rev Res, 3, p.73.

13. Bari, S., Sathe, S., Jain, P. and Surana, S., 2010. Spectrophotometric method for simultaneous estimation of atenolol in combination with losartan potassium and hydrochlorothiazide in bulk and tablet formulation. Journal of Pharmacy and Bioallied Sciences, 2(4), p.372.

14. Devrukhakar PS, Borkar R, Shastri N, Surendranath KV, A validated stability-indicating RP-HPLC method for the simultaneous determination of tenofovir, emtricitabine, and a efavirenz and statistical approach to determine the effect of variables. ISRN Chromatography. 2013 Jan 28; 2013.

15. Dudhe, P.B., Shivarkar N. A., Nagras M. A., (2012). UVSpectrophotometric method development and validation of propranolol hydrochloride and flunarizinedihydrochloride in bulk drug and capsule dosage form, Contemporary Investigations and Observations in Pharmacy, 1(1), 19-23, ISSN No.2278-7429.

16. Komaroju D, Reddy GN, Dhanalakshmi K. Method Development and Validation for Simultaneous Estimation of Emtricitabine and TenofovirDisoproxilFumarate in Pure and Tablet Dosage Form by using RP-HPLC. International Journal of Pharma Research \& Review. 2013 Oct;2(10):1-1.

17. Raju NA, Begum S. Simultaneous RP-HPLC method for the estimation of the emtricitabine, tenofovirdisoproxilfumerate and efavirenz in tablet dosage forms. Research Journal of Pharmacy and Technology. 2008;1(4):522-5.

18. Raju NA, Rao JV, Prakash KV, Mukkanti K, Srinivasu K Simultaneous estimation of tenofovirdisoproxil, emtricitabine and efavirenz in tablet dosage form by RP-HPLC. Oriental Journal of Chemistry. 2008; 24(2):645-50.

19. Mingxing $\mathrm{Hu}, \mathrm{Qi}$ Wang, XiuyingMa,Chao Yang, HongbaoSun,Jie Liu, Yiwen Zhang, Yongmei Xi , A Rapid and Sensitive LC Method for Determination of Diastereomeric Purity of Tenofovir Alafenamide, Chromatographia ,Oct 2014, 77(19) ,1399-1403.

20. B. Khandare, P.B. Dudhe, S. Upasani and M. Dhoke, Spectrophotometric Determination of Vandetanib in Bulk by Area Under Curve and First Order Derivative Methods, International Journal of PharmTech Research, 2019, 12(02), 103-110. 